\title{
PCP: ANÁLISE NO SETOR DE USINAGEM DE UM FABRICANTE DE EQUIPAMENTOS MÉDICOS EM SÃO CARLOS INTERIOR DE SÃO PAULO
}

\section{PCP: ANALYSIS IN THE MACHINERY SECTOR OF A MEDICAL EQUIPMENT MANUFACTURER IN SÃO CARLOS INTERIOR DE SÃO PAULO}

\author{
M. A. B. $\operatorname{COSTA}^{1, *}$, A. L. RODRIGUES ${ }^{2}$, G. SULINO ${ }^{3}$ \\ ${ }^{1,2,3}$ Federal Institute of Education, Science and Technology of São Paulo \\ ${ }^{1}$ Corresponding author. Federal Institute of Education, Science and Technology of São Paulo, Campus São Carlos, SP, Brasil. Phone: +5516997294418 \\ e-mailmarcela.bataghin@ifsp.edu.br (M.A. B. COSTA).
}

\begin{tabular}{l} 
A R T I C L E I N F O \\
\hline Article history: \\
Received 2020-06-24 \\
Accepted 2020-09-04 \\
Available online 2020-09-04 \\
p a l a v r a s - c h a v e \\
PCP \\
Fresa \\
Demanda \\
Ortopedia \\
k e y w o r d s \\
PCP \\
Milling Cutter \\
Demands \\
Orthopedics \\
\hline
\end{tabular}

\begin{abstract}
A B S T R A C T
The company's PCP (Production Planning and Control), responsible for scheduling and controlling production, in addition to coordinating the activities of various departments such as sales, production, purchasing, among others. The article identified bottlenecks in the PCP and in the machining sector of a BRD surgical cutter in a company in the orthopedics sector in the city of São Carlos, SP. Brazil. A bibliographical and documentary review was carried out, followed by a case study. The case study was conducted through a semi-structured interview with a company manager. The data collected made it possible to characterize a company and the manufacturing process of BRD. The result pointed to the communication between the PCP sector and the use of better structuring. Note that the company's PCP does not perform satisfactorily when it comes to a program and controls production.
\end{abstract}

\section{R E S U M O}

\begin{abstract}
O Planejamento e Controle da Produção (PCP) da empresa, responsável por programar e controlar a produção além de coordenar as atividades de vários departamentos como vendas, produção, compras, entre outros. $O$ artigo identificou gargalos no PCP e no setor de usinagem de uma fresa cirúrgica BRD em uma empresa do setor de ortopedia na cidade de São Carlos, SP. - Brasil. Realizou-se uma revisão bibliográfica e documental, seguida de um estudo de caso. O estudo de caso foi conduzido por meio de uma entrevista semiestruturada a um gerente da empresa. Os dados levantados possibilitaram caracterizar a empresa e o processo de fabricação da fresa BRD. O resultado apontou que a comunicação entre o setor de PCP e de usinagem carece de melhor estruturação. Observouse que PCP da empresa não possui um desempenho satisfatório no que se refere a programar e controlar a produção.
\end{abstract}




\section{INTRODUÇ̃̃̃O}

O Planejamento e Controle da Produção (PCP) pode ser definido como um conjunto de ações inter-relacionadas que possuem como objetivo direcionar o processo produtivo da empresa e coordená-lo com expectativas e necessidades dos clientes (Girotti e Mesquita, 2016; Barcelos et al. 2017). Deste modo é possível afirmar que o planejamento é composto por duas etapas importantes no processo: a programação (programar as quantidades e o momento em que os produtos serão fabricados) e o controle da produção (verificar se a programação está sendo de fato cumprida) (Pozo, 2010).

O planejamento da produção é de modo geral responsável por coordenar as atividades de vários departamentos da empresa (vendas, produção, compras, entre outras). Afinal, as informações desses departamentos precisam estar alinhadas para que seja possível prever desvios e buscar maneiras de correção. Segundo Costa (2017), a programação é uma fase intermediária entre planejar e controlar. É a área que, de acordo com a demanda da empresa, transforma os planos que geralmente estão em forma de projetos, listas de materiais, entre outros, em uma agenda de operações que será a base para a emissão de ordens de produção pela gerência de produção.

Conforme Slack et al. (2009), deve haver um alinhamento entre os departamentos de vendas, almoxarifado (estoques), previsão de demanda e produção, para assegurar que o PCP seja eficaz em seus objetivos nas empresas. Os autores corroboram que o PCP é fundamentado basicamente em três pilares: i) planejamento - responsável por determinar quais produtos serão produzidos e quando; ii) programação responsáveis por definir quais recursos serão utilizados desde o início até o término do fluxo de produção; e iii) controle responsável por monitorar e corrigir possíveis desvios e falhas identificados.

Verifica-se atualmente que a busca constante por custos menores e redução a níveis mínimos do total dos desperdícios, tornou-se uma obrigação para as organizações que almejam sobreviver e crescer no mercado. No entanto, as grandes transformações nos cenários econômicos, políticos e sociais ocorridas nas últimas décadas estão fazendo com que a alta administração das empresas façam mudanças radicais nas estratégias e na avaliação de desempenho da produção. Apenas reduzir custos não é suficiente. Além do preço baixo, o produto ou serviço deve vir acompanhado de qualidade, rapidez e confiabilidade. Os clientes exigem cada vez mais produtos inovadores e personalizados, sendo assim, as empresas precisam alcançar flexibilidade e oferecer um mix diversificado, para atender uma demanda crescente e seletiva. $\mathrm{O}$ aumento da demanda leva inquestionavelmente ao aumento de responsabilidade sobre a administração de estoques e materiais (Pozo, 2002).

Esta gestão cabe em parte ao departamento do PCP, que para atender a essas transformações de forma rápida e ampla, vem melhorando cada vez mais seu desempenho, de modo a suprir todas as necessidades, tanto internamente como externamente à empresa. Não importando o tamanho da organização, se esta quer se manter no mercado, deve ter uma gestão adequada de todos os seus processos, e isso não é diferente para o PCP. No entanto, nem todas as empresas, estão preparadas para gerir eficientemente todos os seus processos. Esta falta de preparo é uma realidade para uma empresa do setor de ortopedia situada no Polo de Alta Tecnologia da cidade de São Carlos, estado de São Paulo, objeto de estudo desta pesquisa.

A empresa fabrica produtos de alta qualidade, porém apresenta baixa produtividade, perda de matéria prima e atrasos em razão de problemas relacionados a gestão dos processos produtivos e do PCP. Estes de certa forma elevam o custo de produção, que acabam por ser transferidos aos clientes. Isto é visto como um grave problema, pois, à medida que surgirem novos concorrentes com qualidade equivalente e menores preços a empresa pode perder mercado. Deste modo tem-se como problema de pesquisa a seguinte questão: o que pode ser feito entre o setor de usinagem da fresa cirúrgica e os responsáveis pelo PCP para reduzir perdas no processo de fabricação devido a falhas no planejamento?

Partindo do pressuposto anteriormente pontuado, o artigo objetiva identificar gargalos no PCP e no setor de usinagem na fabricação de fresa cirúrgica da empresa estudada. Como complemento, busca-se verificar possíveis problemas entre o setor de usinagem e o PCP. O estudo têm relevância pois a identificação e eliminação de gargalos nos setores estudados da empresa podem contribuir com a redução dos desperdícios de matéria-prima, reduzindo não apenas os custos de produção, mas contribuindo com a sustentabilidade ambiental e da extração ao descarte dos materiais que são usados sem necessidade.

\section{METODOLOGIA}

Como as pesquisas possuem objetivos diferentes, é comum que se busque classificá-las, uma vez que esta possibilita uma melhor organização e entendimento dos fatos.

Com relação à natureza, esta pesquisa pode ser considerada como aplicada, uma vez que tem como objetivo levantar os problemas existentes e propor melhorias para o processo. Neste caso esta pesquisa é voltada a busca pela solução de problemas e envolve verdades e interesses locais, pois será feito um estudo em uma empresa local de médio porte (Silva e Menezes, 2005). Do ponto de vista da abordagem do problema esta pesquisa pode ser descrita como uma pesquisa qualitativa. Marconi e Lakatos (2011, p.269) afirmam que o método qualitativo difere do quantitativo não só por não empregar instrumentos estatísticos, mas também pela forma de coleta e análise dos dados. No processo de pesquisa qualitativa se interpreta fenômenos e é atribuído significados sem requerer o uso de técnicas e métodos estatísticos. O ambiente natural é a fonte para o pesquisador realizar a coleta de dados e analisar de forma indutiva.

Foi adotado um estudo para a interpretação de fenômenos sem uso de métodos e técnicas estatísticas na pesquisa. $\mathrm{O}$ foco principal da abordagem será os processos, seu funcionamento e o significado destes (Matias-Pereira, 2012). Quanto ao objetivo da pesquisa, esta pode ser classificada como descritiva. De acordo com Rampazzo (2013), a pesquisa descritiva observa, analisa e relaciona fatos ou fenômenos sem interferir nestes. Para Vergara (1998, p.45), a pesquisa descritiva pode estabelecer correlações entre variáveis e definir sua natureza, no entanto, não tem compromisso de explicar os 
fenômenos que descreve, embora sirva de base para tal explicação.

Foi realizado um estudo das características e propriedades de setores específicos de dentro da empresa, ou seja, o setor de usinagem de fresa. Envolveu o uso de entrevista e observações durante a elaboração da pesquisa para levantamento dos dados necessários (Matias-Pereira, 2012). A entrevista realizada seguiu um roteiro semiestruturado. Este tipo de roteiro proporciona liberdade para desenvolver a situação, permitindo explorar mais cada questão.

Os procedimentos técnicos selecionados foram a pesquisa bibliográfica e pesquisa documental. A bibliográfica é elaborada com base em material já publicado, principalmente de livros, artigos publicados em anais de congressos e periódicos, banco de teses e dissertações, revistas especializadas entre outros. Segundo Gil (2010), praticamente toda pesquisa acadêmica requer uma pesquisa bibliográfica, e sua principal vantagem é permitir ao investigador uma série de situações muito mais ampla do que se pode observar diretamente.

Para Vergara (1998, p.46), a pesquisa documental é a

\section{RESULTADOS E DISCUSSÃO}

\subsection{Caracterização da empresa}

A empresa estudada foi fundada no ano de 2005, na cidade de São Carlos, estado de São Paulo - Brasil. A localização da empresa está diretamente relacionada com o fato de São Carlos ser conhecida como a ñCapital da Tecnologiaò. Além disso, a localização da empresa é estratégica, visto a facilidade de escoamento da produção para outras cidades do Brasil e para o exterior. A empresa inova constantemente e fabrica produtos variados para procedimentos de artroscopia; bucomaxilo; cirurgia de mãos e pés; coluna; neurocirurgia; ortopedia e otorrinolaringologia.

O principal respondente (entrevistado) tem formação superior no curso de Tecnólogo em Processos Gerencias, e é o gerente responsável do setor de usinagem e do setor de produção de protótipos. Está na empresa há 12 anos e foi o primeiro funcionário a ser contratado, deste modo adquiriu ao longo do tempo conhecimento da prática da empresa em todos os setores. A empresa estudada desempenha um papel estratégico no cenário da ortopedia brasileira. A gama de produtos oferecidos incorpora as áreas de eletrônica fina, óptica, mecânica fina e química, abrangendo praticamente todos os segmentos da cirurgia ortopédica.

Apenas para esclarecimentos, as áreas de eletrônica fina e mecânica fina, é um campo multidisciplinar da engenharia, que estuda e desenvolve produtos de alta precisão, sendo de extrema importância para os produtos desenvolvidos pela empresa. A mecânica está relacionada com toda a produção do setor de usinagem, enquanto a eletrônica é fundamental na montagem dos produtos. Já a óptica é o ramo da física responsável por estudar os fenômenos da luz e da visão humana, área que se faz necessária para equipamentos destinados a cirurgias que necessitem de imagens nítidas para um bom resultado cirúrgico, enquanto a química é a ciência que estuda a composição, estrutura e propriedades da matéria, essencial para escolha dos materiais e o tratamento químico investigação realizada em documentos conservados no interior de órgãos públicos e privados de qualquer natureza, ou com pessoas: registros, anais, regulamentos, circulares, ofícios, memorandos, balancetes, comunicações informais, filmes, microfilmes, fotografias, vídeos informações em disquete, diários, cartas pessoais, relatórios, comunicação, atas de reunião, entre outros.

Em seguida foi realizado um estudo de caso, que de acordo com Gil (2010, p.37) é uma modalidade de pesquisa amplamente utilizada nas ciências sociais e sociais aplicadas. Consiste no estudo profundo de um ou poucos objetos, de maneira que permita seu detalhamento. Neste caso, busca-se analisar as atividades relacionadas ao PCP do setor de usinagem de fabricação de fresa em uma empresa, ou seja, de um único objeto e identificar possíveis falhas que levam a perdas de matéria prima e atrasos na produção. Deste modo atende ao requisito de desenvolver um estudo profundo a fim de se conhecer detalhadamente o objeto estudado. Assim, a pesquisa analisou uma empresa de alta tecnologia fabricante de equipamentos médicos e hospitalares situada na cidade de São Carlos, interior do estado de São Paulo, Brasil.

pelo qual os produtos passam.

A empresa classifica-se como de médio porte (177 colaboradores). Estes funcionários são distribuídos entre diversas áreas, tais como: o departamento de produção (99) funcionários; a qualidade (18); os setores administrativos (14); planejamento e compras (10); desenvolvimento de produtos (13) e demais áreas como limpeza, segurança do trabalho, manutenção predial e motorista (17).

A empresa possui administração familiar, sendo os dois sócios fundadores os principais gestores. É constituída exclusivamente de capital nacional, porém exporta seus produtos para diversos países, como Colômbia, Bolívia, Republica Dominicana e África do Sul. Os produtos fabricados são constituídos de aço inox e titânio, e seus componentes internos de alumínio e latão. A empresa possui um processo produtivo padronizado e suas ordens de produção são geradas em lotes, desse modo as quantidades são fabricadas para estocar e suprir a demanda da semana seguinte. Há casos extraordinários nos quais os produtos são personalizados e produzidos sob encomenda.

Como a empresa produz para estocar e suprir a demanda da semana seguinte, os gestores não fazem uma previsão de demanda utilizando técnicas adequadas. A empresa só se baseia na demanda da semana anterior verificada pelo responsável do PCP. Porém, em muitos casos, esta técnica de fazer previsão observando apenas o passado, mesmo que recente, acaba não sendo efetiva, pois a empresa recebe novos pedidos que acaba superando os itens que ela tem em estoque e já estão comprometidos para outro cliente.

Desse modo, verifica-se uma falha de comunicação entre o setor de produção, PCP, vendas e previsão de demanda. A especialidade da empresa é produzir produtos voltados para artroscopia, bucomaxilo, cirurgia de mãos e pés, neurocirurgia, coluna ortopedia e otorrinolaringologia, vide Tabela 1. A empresa possui certificação de qualidade de Boas Práticas de Produção, pois seus produtos se direcionam para o uso cirúrgico hospitalar, o que torna obrigatório essa certificação. 
No entanto, no dia a dia não se verificam de fato a aplicação

destas boas práticas.

Table 1 - Especialidades e linhas de produtos fabricados na empresa estudada Especialidade Produtos

Artroscopia

Shaver, Trocater, laminas, Instrumentais, É usada principalmente como método Endoscópio, Eletrodo e Equipo de cirúrgico para reparar lesões intraIrrigação.

Bucomaxila

Cirurgia de Mãos e Pés

Neurocirurgia

Coluna

Ortopedia

Otorrinolaringologia
Shaver, Drills, Micro Serra, Laminas, Fresa Cirúrgica e cânulas.

R Blade, Fresa Cirúrgica, Gancho, Shaver, Lamina, Trocater, Drill, Malha de Tração e Micro Serra.

R Force, Brocas para Crânio, Fresas Diamantadas, Equipo de Irrigação e Drill.

Shaver, Drill, Fresa Cirúrgica, Kit Cânula e Gancho de Distração.

Shaver, Micro Serra, Drill, EuroScrew, Instrumental para parafuso e Trocater.

Shaver, Cânula ENTM, Micro Serra, Fresa Cirúrgica, Eletrodo, Laminas Mini e Drill. articulares.

São utilizados para tratar cirurgicamente as doenças e fraturas da cavidade bucal, face e pescoço.

Produtos utilizados para tratamento cirúrgico de mãos e pés e cirurgia percutânea de pé.

Dedica-se ao tratamento de doenças e lesões do sistema nervoso central e periférico.

Produtos para métodos minimamente invasivos em cirurgia de coluna.

Procedimentos Ortopédicos, reconstrução de ligamento,

Dedica-se as cirurgias que acometem a orelha, o nariz e a garganta.
Constatou-se durante o estudo que a empresa não tem conhecimento de sua capacidade produtiva total. Isso também é considerado um gargalo, visto que ela pode estar com capacidade ociosa (perdendo vendas) ou não estar conseguindo cumprir com sua produção total (algo que não é notado devido à produção para estoque). Conforme Slack et al. (2009), é de interesse da administração de produção determinar a capacidade efetiva da operação produtiva, para assim satisfazer a demanda atual e futura, mantendo ainda um equilíbrio adequado entre capacidade e demanda.

Esta falha poderia ser corrigida com a implantação e operacionalização correta de um sistema de controle de produção e com um responsável que alimentasse o sistema com dados corretos. O PCP tem entre suas funções planejar e controlar a produção e isto envolve definir e acompanhar quando e quanto de matéria prima é requerida para cada produto fabricada. Por isso é importante se ter uma lista (Bill of Materials) de quais materiais são necessários para cada produto.

Além disso, a empresa não tem um sistema que possibilite uma troca rápida de informações com os fornecedores. A empresa não trabalha com estoque suficiente para conseguir produzir, caso haja atraso de algum fornecedor, ou seja, ela tem estoque de produtos acabados, mas não possui estoque de matéria-prima e não trabalha com o sistema Justiin-Time, assim, o fornecimento é demorado e pode comprometer a entrega do produto final caso falte algum item na montagem.

O setor de PCP não tem uma comunicação adequada com o setor de usinagem, sendo que o responsável pelo PCP apenas passa uma lista com os itens a serem produzidos na semana. O problema é que o responsável pelo PCP não conhece a capacidade produtiva total da empresa, e em muitos casos, diversos itens dessa lista nem se quer faz parte dos itens estocados. Quando isto ocorre o responsável pela usinagem, traça a sequência de produção (deixando por último o item cuja matéria prima inexiste na empresa) de modo a ganhar tempo na produção.

Atualmente a empresa tem alto índice de desperdício de matéria-prima, acarretado pela falta de procedimentos técnicos. De forma contraditória há também insuficiência de matéria prima (devido ao desperdício), gerando atrasos nas entregas dos pedidos devido a um estoque insatisfatório, pois, a empresa não possui um controle de quantos dias são necessários para que cada pedido feito a um fornecedor chegue à empresa. Isso aponta para existência entre o PCP e o setor de usinagem.

Em alguns casos, a falta de matéria prima ocorre para a fabricação de produtos considerados de extrema urgência, e para não haver atrasos é utilizado um material maior do que estipulado, gerando uma perda de material desnecessária, um maior gasto de ferramentas e aumento do tempo da fabricação.

Estes problemas podem ser considerados graves e utilização de cronogramas e gráficos de processos poderiam resolver problemas internos. Quanto aos fornecedores, atualmente já se tem muitos programas que integram empresas e fornecedores, o que facilitaria o controle desde o pedido até a entrega. A adoção de um sistema mais robusto de previsão de demanda e lote econômico de compras também ajudaria a evitar estes tipos de problemas.

Como citado na literatura, o PCP engloba o plano estratégico de negócios, responsável pelo elo que estabelece os objetivos e metas que a empresa espera atingir no curto, médio e longo prazo. Observou-se que na empresa não existe um plano estratégico formalizado. $\mathrm{O}$ crescimento da empresa e aumento do volume de produção se deve exclusivamente a alta qualidade de seus produtos e a pouca existência de 
concorrência.

\subsection{Processo produtivo de fresa cirúrgica}

A fresa cirúrgica é um instrumento usado na área médica para desbaste e perfuração de ossos. Neste trabalho a fresa estudada será o modelo BRD, que são fresas redondas destinadas a cortes ósseos e acabamentos moderados. Este produto tem demanda média de 1600 unidades por mês, sendo possível fazer uma combinação de 7500 modelos diferentes (alterando apenas o diâmetro da fresa e encaixe).

Nos últimos anos foram vendidos 3500 modelos diferentes de fresas. Este produto representa uma parte considerável do volume de produção. $\mathrm{O}$ processo de fabricação da fresa, assim como todo produto no processo produtivo, tem início a partir do processamento de pedido. O pedido por sua vez parte do cliente. $\mathrm{O}$ cliente faz o pedido diretamente para o representante de vendas, que o encaminha para o setor do PCP de empresa. Em seguida o PCP gera a Ordem de Produção (OP) da fresa. Este encaminha para o departamento de controle de qualidade a folha contendo a da Ordem de Produção com o número da ordem e do desenho. Ressalte-se aqui que cada fresa possui um desenho próprio identificado por números.

Em seguida o departamento de qualidade anexa o desenho impresso e a folha de processo e entrega toda a documentação para o responsável pelo setor de Usinagem. Este por sua vez decidirá o momento e em qual máquina será feita a usinagem da fresa, levando em consideração a máquina que está com uma preparação mais adequada á peça que será produzida, analisando ainda a sequência de prioridades da entrega dos pedidos, conforme Figura 1.

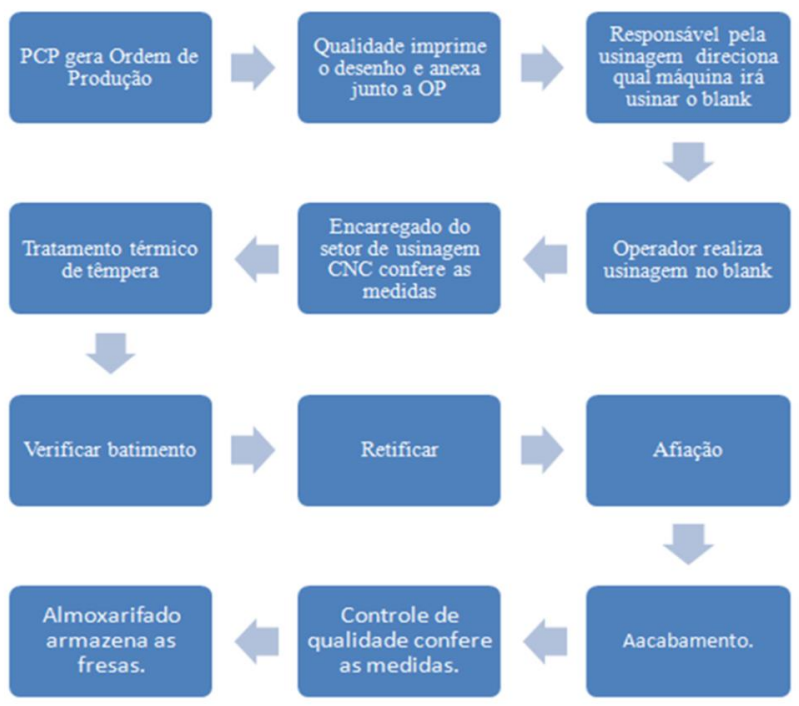

Figura 1 - Processo de fabricação de fresa cirúrgica

Assim que uma decisão for tomada (com relação á máquina e sequência de produção) a OP é enviada para o operador da máquina (centro de torneamento) que fará a primeira operação, que é usinar o blank (peça usinada a partir de um material bruto, que após os processos se tornará uma fresa), conforme mostra Figura 2.

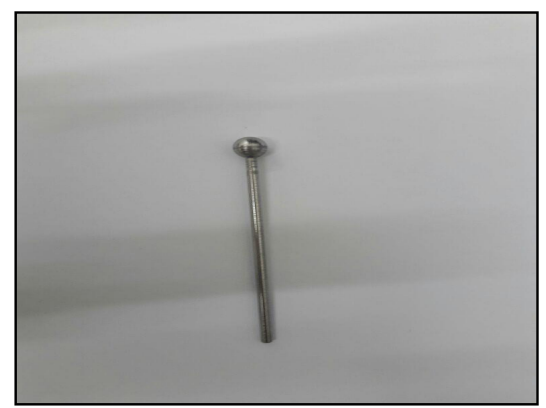

\section{Figura 2 - Blank após a primeira usinagem}

Ao final da usinagem do Blank, o operador lhe entrega para o líder do setor que confere as dimensões e acabamento visual e passa para o próximo processo, denominado têmpera. Neste momento o funcionário executará esse processo colocando as peças no forno de acordo com tempo e temperatura pré-estabelecidos, resultando na Figura 3.

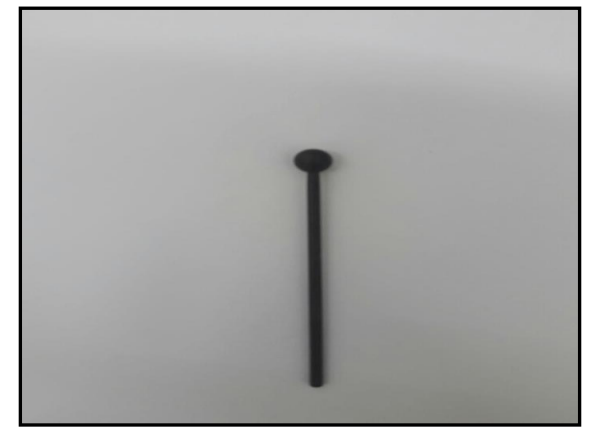

Figura 3 - Blank após processo de Têmpera

Após o processo de têmpera, o operador verificará o batimento dos blanks utilizando o relógio comparador, pois o tratamento térmico faz com que as peças fiquem empenadas. Em seguida este funcionário entrega estas peças para o seu encarregado que o designará para a próxima etapa, que será retificar a haste do corpo do blank, conforme Figura 4.

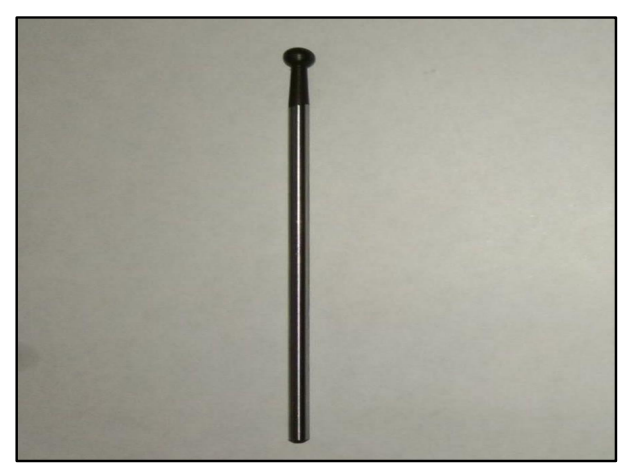

Figura 4 - Blank após retífica

Posteriormente, o Blank vai para as afiadoras (máquinas $\mathrm{CNC}$ ) onde será usinado o corte na ponta da fresa. Afiadas, as fresas são enviadas para o setor de acabamento para que sejam eliminadas as rebarbas, ou seja, as sobras. Após o acabamento, o funcionário designado para esta função o encaminhará para o controle de qualidade onde será feita a inspeção dimensional, verificado o acabamento superficial e sua resistência. A fresa finalizada é mostrada na Figura 5. 




\section{Figura 5 - Fresas prontas}

Alguns desenhos já chegam para o operador com certos encaixes especificados. Estes encaixes já serão usinados na primeira operação, outros vão para o almoxarifado e depois voltam para usinagem com outra ordem de produção para que se usinem o encaixe. A Figura 6 apresenta os modelos de encaixes.

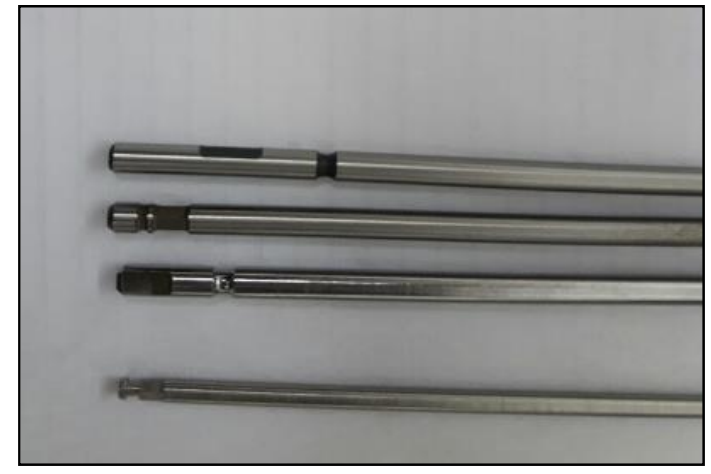

Figura 6- Modelos de encaixes

Importante ressaltar que como citado por Slack, Chamber e Johnston (2009), a previsão de demanda é uma informação importante para o planejamento de negócio, pois proporciona as condições necessárias para que a empresa se planeje em termos de capacidade produtiva (força de trabalho, instalações e equipamentos) e materiais necessários para a produção, sendo que a primeira questão a ser decidida é a escala de tempo para suas previsões. Ao serem questionados sobre a previsão de demanda, os respondentes afirmaram não ser possível fazer esta previsão na empresa. Esta constatação indica que de fato em algum momento vai sobrar matéria prima, gerando todos os custos incorridos de estoque e em outros momentos podem faltar matéria, levando consequentemente a atrasos na entrega, insatisfação dos clientes e uma possível perda de clientes.

Pôde-se observar que durante o processo de fabricação das fresas cirúrgicas acontecem muitos setups, o que gera custo, pois algumas vezes usa-se gaste-se mais tempo com os setups do que com a própria produção. Como citado tal prática poderia ser evitada utilizando-se do LEC que segundo Costa (2017), é o tamanho do lote ideal que minimizaria estes custos. Observou se que a empresa não se preocupa com os tamanhos dos lotes, quantidades de paradas e com a própria perda de matéria prima, principalmente por não possuir muitos concorrentes, repassando estes custos para os clientes. Neste ponto pôde-se observar que mesmo podem ocorrer danos que acabam sendo repassados para consumidores finais e além de um dano ao meio ambiente.

Em alguns momentos os líderes da usinagem ficam sobrecarregados, pois além de suas funções acabam acumulando outras, como delegar e organizar quais OP's devem entrar na produção. Uma previsão correta na demanda poderia auxiliar o setor de PCP a fazer um controle correto e deixar melhor organizado para que os operadores não dependessem de seus líderes para saber qual OP deverá produzir. Outra constatação feita é de que a empresa possui estoques tanto de matéria-prima (que as vezes é usado sem necessidade), quanto de materiais em processamento e de produtos acabados.

É de conhecimento que estoques geram diversos custos. Ao serem questionados sobre a adoção de alguma tática de redução de estoques os respondentes não souberam responder, mostrando um desconhecimento de medidas que além de reduzir os estoques tem como consequência a redução de seus custos.

Como já mencionado, a empresa acaba repassando estes custos, para s para os consumidores. Este é um dos motivos para não adoção de medidas de redução de estoques ou até mesmo de eliminação destes. A empresa confia que a qualidade de seus produtos irá mantê-los no mercado, mesmo nos dias de hoje, quando é possível adquirir produtos de qualquer lugar do mundo e às vezes com menor preço e qualidade semelhante. Além disso, já se tem conhecimentos de possíveis novos entrantes no mercado em que a empresa atua. Num futuro próximo, essa prática pode ser extremamente prejudicial para a empresa. A partir do exposto acima, resume-se os principais gargalos encontrados na usinagem da fresa cirúrgica:

A empresa desconhece sua capacidade produtiva total; e isto ainda não é visto como um problema sério, pois a empresa mantém estoque (ainda que sem controle que quais itens estão estocados). No entanto no futuro próximo pode vir a ser um problema sério visto que estoques geram altos custos, além de esconder problemas nas linhas de produção;

- Desperdício de matéria prima, pois a empresa muitas vezes usa materiais com diâmetros maiores para fabricar um produto que não necessitaria da quantidade excessiva de matéria-prima (blank), a fim de substituir o material correto que está em falta em seu estoque. Deste modo o que sobra não é mais passível de uso, sendo descartado, gerando perdas financeiras e prejuízo ao meio ambiente;

- $\quad$ Altos custos de produção, devido a perdas de matériaprima;

- $\quad$ Falta de controle sobre tempos para fabricação;

- Falta de controle sobre as quantidades corretas de fabricação;

- $\quad$ Falta de controles sobre tempos de ressuprimento;

- Falta de um sistema que ligue diretamente a seus fornecedores;

- Comunicação falha entre os setores de PCP e usinagem; 
ÅOs principais fornecedores estão longe da empresa, dificultando a entrega rápida de algum item faltante no estoque e;

ÅFalta de uma previsão de demanda.

\section{CONCLUSÃO}

O PCP é fundamental para gerenciar as atividades produtivas, dando suporte e sendo o responsável pela melhor alocação dos meios disponíveis, de modo a estabelecer uma combinação entre as necessidades e as operações para cumprir com a produção demandada. Quando bem executado, proporciona para a empresa, um bom ritmo de produção e evita perdas e gargalos, assegurando a sua sobrevivência no futuro. Sendo assim, o presente trabalho identificou e analisou gargalos no PCP e no setor de usinagem na fabricação de uma fresa cirúrgica em uma empresa de equipamentos hospitalar localizada na cidade de São Carlos, estado de São Paulo Brasil.

Verificou-se que a empresa não possui um sistema adequado de previsão de demanda, mantendo altos volumes de estoques sem saber exatamente quais itens estão estocados. Além disso, existem falhas de comunicação entre os departamentos de PCP, usinagem e demais setores que deveriam trabalhar interligados. Apesar dos problemas internos, a empresa fornece a seus clientes produtos com alta qualidade e, como ainda não existem muitos concorrentes no mercado, consegue repassar o custo de sua produção.

Observou-se também que é excessivo o desperdício de matéria prima. A empresa mantém estoque de matéria prima, no entanto, às vezes não tem a matéria prima necessária para uma determinada fresa. Deste modo, usa-se um blank maior para usinar a fresa BDR. Depois de usinada, o blank é perdido, gerando custos desnecessários.

A comunicação entre os setores de PCP e de usinagem é falha, sendo fornecido para o setor de usinagem somente uma lista com relação de itens que devem ser produzidos, a tomada de decisão de qual máquina e qual momento será usinado fica a critério dos responsáveis pela usinagem. Constatou-se durante o estudo que a empresa possui um sistema responsável por realizar requisições de materiais, consultas de estoque (tanto matéria prima, como produtos semiacabados e acabados) e de emissão de ordens de produção, porém este não é alimentado e nem utilizado de maneira adequada. Isto faz com que mesmo mantendo estoques a empresa conviva com falta de matéria prima para a fabricação de seus produtos, o que mostra a falta de uma gestão apropriada de estoque e reforça a necessidade de interligação e comunicação entre departamentos que exercem as funções principais da produção.

Sugere-se que a empresa realize um estudo de sua capacidade produtiva mensal, com objetivo de melhor se organizar e evitar possível tempo ocioso de máquinas e mão de obra ou sobrecarga que resulta em atrasos na entrega dos produtos. $\mathrm{O}$ conhecimento dessa informação pode trazer como benefício um aumento da capacidade de oferta dos produtos e até mesmo uma redução dos custos na fabricação.

\section{R E F E R E N C E S}

BARCELOS, R. L. et al. Sistema de informações para processo de planejamento e controle da produção: estudo de caso aplicado a uma indústria de confecção. Exacta - EP, São Paulo, v. 15, n. 4, p. 155-165, 2017.

COSTA, M. A. B. Logística: estoque, distribuição e logística reversa. $1^{\text {a }}$. ed. Santa Cruz do Rio Pardo: Viena, 2017. 160.p.

CREPALDI, A.; TOMAZINI, C.; LEMES, F.; BERNARDO, M.; CRISTINA, T.; TEZZOTTO, T.; NAKAHARA, T. H. O. Planejamento e controle da produção. 2011. 26p. Material Didático. UNISO. Sorocaba.

GIL, A. C. Como Elaborar Projetos de Pesquisa. 5a ed. São Paulo: Atlas, 2010.

GIROTTI, L. J.; MESQUITA, M. A. Simulação e estudos de caso no ensino de planejamento e controle da produção: um survey com professores da engenharia de produção. Production, São Paulo. vol. 26, n.1, -.176-189, 2016.

MARCONI, M. A.; LAKATOS, E. M. Metodologia Científica. $5^{\mathrm{a}}$ ed. São Paulo: Atlas, 2011.

MATIAS-PEREIRA, J. Manual de Metodologia da Pesquisa Cientifica. $3^{\text {a }}$ ed. São Paulo: Atlas, 2012.

POZO, H. Administração de recursos materiais e patrimoniais: uma abordagem logística. $2^{a}$. ed. São Paulo: Atlas, 2002. p.30.

POZO, H. Administração de recursos materiais e patrimoniais: uma abordagem logística. 6 ${ }^{a}$. ed. São Paulo: Atlas, 2010 .

RAMPAZZO, L. Metodologia Cientifica. $7^{\mathrm{a}}$ ed. São Paulo: Loyola, 2013.

SILVA, E. L.; MENEZES, E. M. Metodologia da pesquisa e elaboração de dissertação. $4^{\mathrm{a}}$. ed. Florianópolis: UFSC, 2005.

SLACK, N.; CHAMBERS, S.; JOHNSTON. Administração da Produção. $3^{\mathrm{a}}$ ed. São Paulo: Atlas, 2009.

VERGARA, S. C. Projetos e Relatórios de Pesquisa em Administração. $2^{\mathrm{a}}$ ed. São Paulo: Atlas, 1998. 